\title{
SEGURANÇA CONTRA INCÊNDIO EM EDIFICAÇÕES: UMA VISÃO SOB O ENFOQUE DA GESTÃO DO CONHECIMENTO
}

\author{
Sérgio Stein ${ }^{1}$ \\ Denílson Sell ${ }^{2}$
}

\section{RESUMO}

O presente artigo tem por objetivo descrever o considerado "Sistema de Segurança Contra Incêndio em Edificações dos Estados Unidos(SSCIE/EUA)", na dimensão de Códigos \& Normas (C\&N) - em inglês: Codes \& Standards ${ }^{3}$ $\left(C \& S^{4}\right)$, sob o enfoque da Gestão do Conhecimento (GC), identificando seus principais atores, relações e fluxos de conhecimento, abordando dimensões qualitativas, à luz doconhecimento, o que pode ser ponto de partida para 0 desenvolvimento de ações envolvendo a governança e capacitação do SSCIE/BR ${ }^{5}$.Para tanto, foi utilizado a técnica de diagramação sistêmica denominada systemigrams, identificando os elementos-chave, com atenção especial às partes, relacionamentos e fluxos. Uma versão do systemigram do SSCIE/EUAé apresentada, elaborada a partir da análise de documentos e entrevistas com especialistas em Segurança Contra Incêndio em Edificações dos EUA (SCIE/EUA). Oestudo se reveste de notória relevância econômica e social e inaugura um nível de abordagem até então inexistente.

Palavras-Chave: Segurança Contra Incêndio. Edificações. Gestão do Conhecimento. Systemigram.

\footnotetext{
1 Oficial do Corpo de Bombeiros Militar de Espírito Santo. Chefe do Departamento de Gestão do Conhecimento do CBMES. Mestrando em Gestão do Conhecimento PPGGC - UFSC.

2 Professor Doutor de Professor Doutor do Programa de Pós-Graduação em Gestão do Conhecimento - PPGEGC/ UFSC

${ }^{3}$ Codes \& Standards - ao contrário da maioria de outras regulamentações estaduais e federais nos EUA, os códigos (Codes) modelos de construção e incêndio, juntamente com os padrões (Standards) referenciados pelos códigos modelo, não são desenvolvidos por agências governamentais, mas são desenvolvidos por organizações do setor privado.

${ }^{4}$ C\&S-para efeito desse artigo, esta abreviatura também se refere aos Códigos \& Normas brasileiros.

${ }^{5} \mathrm{SSCIE} / \mathrm{BR}-$ entendido como o conjunto dos C\&S dos entes Federados brasileiros.
} 


\title{
ACCESSIBILITY AND SAFETY IN FIRE EVACUATION FOR PEOPLE WITH DISABILITIES
}

\begin{abstract}
The purpose of this paper is to describethe "United States Building Fire Safety System (BFSS/US)" in the Codes \& Standards dimension under the Knowledge Management approach, identifying its main actors, relationships and knowledge flows, approaching qualitative dimensions, in the light of knowledge, which can be the starting point for the development of actions involving the governance and capacity building of BFSS/BR. In order to do so, we used the technique of systemic diagramming called systemigrams, identifying the key elements, with specialattention to the parts, relationships and flows. A version of the BFSS/USsystemigramis presented, based on document analysis and interviews with US Building Fire Safety Specialists. The study is of notable economic and social relevance and inaugurates a level of approach that did not exist until then.
\end{abstract}

Keywords: Fire Safety. Buildings. Knowledge Management. Systemigram.

Artigo Recebido em 30/11/2019 e Aceito em 01/07/2019 


\section{INTRODUÇÃO}

O Sistema de Segurança Contra Incêndio em Edificações - SSCIE é composto por diversos atores, possuidores de tipos e naturezas de conhecimento dos mais diversos, desempenhando papéis específicos, contribuindo para a melhoria contínua da SCIE, com destaque para os Corpos de Bombeiros, Fabricantes de Equipamentos, Prestadores de Serviços, Academia, Poderes Constituídos, Sociedade Civil Organizada e Consumidores(STEIN, SELL e GODINHO, 2018, p. 148).

Nos Estados Unidos da América - EUA a Segurança Contra Incêndio (SCI) e por consequência a SCIE é alimentada por uma ampla e bem organizada política nacional e conta com uma bem articulada interação dos seus principais atores em uma verdadeira arena do conhecimento, com especial produção de C\&S de salvaguarda da vida e do patrimônio, com relevante repercussão econômica e social. O Governo Federal é o grande articulador e fomentador de políticas públicas relacionadas à $\mathrm{SCl}$ e em especial a SCIE, com destaque para o U.S. Fire Administration(USFA) / National Fire Academy(NFA) e o National Institute of Standards and Technology(NIST). Os principais produtores de conhecimento do SSCIE/EUA que fornecem o Estado da Arte do Conhecimento ${ }^{6}$ - Governo Federal, Companhias de Seguro e Certificadores, Organizações Sociais e Privadas, Industria, Governo Local e a Academia - e junto da ampla gama de conhecimento profissional dos stakeholders, mantêm o SSCIE/EUA funcionando em elevados níveis.

O objetivo do artigo é descrever o SSCIE/EUA, aqui tomado como referência, na dimensão de C\&S, sob o enfoque da Gestão do Conhecimento $\mathrm{GC}$, identificando seus principais atores, relações e fluxos de conhecimento, abordando dimensões qualitativas, à luz do conhecimento, o que pode ser

\footnotetext{
${ }^{6}$ Estado da Arte do Conhecimento - aqui considerado como o conhecimento acumulado ao longo da história que pode ser evidenciado em produtos, procedimentos, processos, técnicas ou ciência.
} 
ponto de partida para o desenvolvimento de ações envolvendo a governança e capacitação do SSCIE/BR. Para tanto, foi utilizado a técnica de diagramação sistêmica denominada systemigrams, identificando os elementos-chave de um modelo de sistema formal, com atenção especial às partes, relacionamentos e fluxos.

É imperioso construir consensos e harmonias nos temas relevantes para os stakeholders, a exemplo dos C\&S de SCIE, que impõe: como construir, como equipar e como proceder na preservação e proteção da vida, em primeiro lugar, em toda e qualquer edificação.

A GC, radical e radialmente, pode operar $360^{\circ}$ com possibilidades, ferramentas, métodos e tecnologias, capazes de apoiar, melhorar e permitir rumos e decisões mais acertadas, atualizar e refinar competências, além de prover condições para uma melhor governança e navegação no contexto vivido de riscos e demandas exacerbadas, e, aquelas por vir a lume, sabidamente bem mais complexas. A GC constrói a memória institucional, um ativo de produção e gestão e insere-se no Ecossistema Bombeiros senso amplo, fortalecendo ainda mais os vínculos com parceiros extramuros, ampliando interfaces com a academia, fabricantes, fornecedores, prestadores de serviços e comunidades, além de reforçar as conexões e sinergias na teia das relações do território de atuação.

No Brasil a ausência de uma política nacional e uma pobre interação dos principais atores é refletida na produção ou mesmo na adaptação/compilação de C\&S estrangeiros, com importante repercussão econômica e social ainda não medida.

\section{SCIE/EUA}

É vital olharmos como historicamente os EUA chegaram até os dias atuais na pesquisa de SCIE: cada estado tem seu próprio conjunto de estatutos para as leis estaduais, normas e decretos. São aprovadas as melhores práticas para proteger os cidadãos em termos de segurança para a vida, SCIE e 
construção segura de edifícios. Há 45 anos, o Congresso dos EUA produziu um relatório que levantou os principais problemas de SCI dos EUA e possíveis soluções, pois não havia uma pesquisa unificada de $\mathrm{SCl}$ que ajudasse o país. Esse relatório deu origem a publicação nomeada de America Burning. A Comissão responsável por esse relatório fez recomendações para reduzir as perdas de vidas e ferimentos devido a incêndios (FEDERAL EMERGENCY MANAGEMENT AGENCY, 1987).

A Comissão chegou à conclusão de que a educação e a prevenção da $\mathrm{SCl}$ eram críticas na redução de vítimas associadas a incêndios. Ainda, o relatório constatou que os departamentos de incêndio, durante anos, trabalharam isoladamente e que o compartilhamento de informações era lento e quase inexistente. Após quatorze anos da publicação do America Burning, o Congresso dos EUA aprovou a Lei Federal de Prevenção e Combate a Incêndios e então se deu o sentimento de que o serviço de bombeiros enfim estava canalizando uma nação unificada para abordar a $\mathrm{SCl}$ e a prevenção de incêndios.

O Congresso também direcionou o NIST para conduzir pesquisas sobre incêndios em muitas das questões de $\mathrm{SCl}$ e materiais de construção e produtos utilizados na construção de todos os edifícios. Muitas universidades e outras organizações começaram a compartilhar suas descobertas de pesquisas devido ao recebimento de subsídios para ajudar na pesquisa, com muitos engenheiros e cientistas realizando 0 trabalho fundamental. Esses especialistas em pesquisa de $\mathrm{SCl}$ mostraram ótimos resultados como a redução de mortes por incêndio e perdas de propriedades através de seus estudos e resultados de pesquisa (CLEMENS, 2018). 


\section{GESTÃO DO CONHECIMENTO}

A GC se popularizou no final dos anos 80 com o aparecimento de muitas publicações e eventos relacionados ao tema. Embora o termo seja recente, o ser humano ao longo de sua história acumula experiências da vida em comunidade, encontrando diversas maneiras de compartilhar 0 conhecimento, construindo sobre suas experiências anteriores, eliminando custos, redundâncias e evitando cometer os mesmos erros novamente. Portanto não é de hoje que o homem pratica GC (DALKIR, 2017).

A GC insere-se vigorosamente no ecossistema dos Corpos de Bombeiros, cuja teia amplia-se, necessariamente, nas interfaces com a Academia, Indústria e com as Comunidades de Prática ou Comitês, na construção da resiliência atual e futura dos serviços prestados. A GC contribui ainda no enfrentamento aos desafios e demandas colocadas: recursos econômicos e financeiros públicos escassos e decrescentes, insuficiência de conhecimento aplicado, dos mais básicos (Estatísticas nacionais confiáveis sobre incêndios, integradas e compartilhadas, por exemplo), no urgente enfrentamento das lacunas e demandas por tecnologias e ativos operacionais e de gestão, na governança interna e relacioná-la aqueles conhecimentos ainda estão por ser gerados, apreendidos ou adaptados e adotados nas corporações.

Por exemplo, Bombeiro 4.0 (Big Data / Cloud Computing, Blockchain, Ensaios em Diversas Escalas - Destrutivos e Não-destrutivos, Simulação Computacional de Alto Desempenho; I.o.T., I.A., Smart Sensors, Digital Twins, VR Imersiva e Interativa, Equipamentos Autônomos / Robóticos / Drones Inteligentes) evoluindo no horizonte bem próximo de eventos. Busca-se então conhecer, apurar e mapear possibilidades e territórios, constituir memórias e repositórios úteis, monitorar e compartilhar resultados e possibilidades, recomendar e atualizar sugestões quanto a aplicação sistêmica, chama inicial do esforço deste estudo. 
No Brasil, de maneira geral os Corpos de Bombeiros Militares (CBM) com suas atribuições constitucionais, prerrogativas legais e regulatórias, provocam muitos impactos no cotidiano das pessoas e das organizações. No aspecto social, o impacto maior, nas vidas a preservar e salvar, com riquezas e patrimônios sob o mesmo arco de proteção. Além de combatentes do fogo, são a primeira resposta em emergências e desastres, com atribuições de resgate, salvamento e apoio a vida em terra, mar e $\operatorname{ar}(24 \times 7)$.

Também é impactada a cadeia de valor de todos os segmentos da produção, dos serviços, e do convívio seguro em comunidade (requisitos de segurança obrigatórios, prazos, dispêndios com taxas, projetos, especialistas, atendimento e adequação física e legal às normas e exigências regulatórias), construção civil, setores imobiliários e de seguros, porto, indústria, entretenimento e turismo, dentre muitos outros, pois ao mesmo tempo em que elaboram os C\&S, os CBM's emitem os alvarás, concedem as licenças, fiscalizam e vistoriam as conformidades, notificam e multam as inconformidades, fazem perícias, homologam e validam equipamentos, sistemas, processos, protocolos e procedimentos.

Afinal os C\&S de salvaguarda, preservação e proteção a vida, nos dizem e indicam como edificar, como equipar, e também como proceder em certos casos, pois nos dizem e orientam como conviver e nos relacionar em segurança em diversos espaços urbanos, inclusive nossos lares.

A GC através de práticas ou ferramentas de colaboração e tecnologias fornecem a capacidade de interagir com especialistas e aumenta 0 conhecimento e retenção das melhores práticas de $\mathrm{SCl}$. Por exemplo, permite uma visita virtual a um projeto de pesquisa e teste de incêndio - Chat com vídeo ao vivo e interação e colaboração individual com atividades on-line podem estar em qualquer lugar do mundo. Isso dá uma ampla gama de recursos para conduzir pesquisas SCIE.

Por exemplo, articular comunidades de práticas ou comitês em torno 
das tecnologias nucleadoras do seu mister - propor normas, vistoriar equipamentos e instalações, fiscalizar quanto ao uso e conformidade, aprovar a instalação, requer a composição de grupos de aprendizagem com os projetistas, conectando-os permanentemente para o mutuo conhecimento, entendimento e domínio dos ciclos evolutivos das tecnologias aplicadas e das etapas/gestão de projetos, especialmente dos sistemas em uso no território de atuação.

O compartilhamento do olhar e da percepção do vistoriador com o olhar e a percepção do projetista, a compreensão dos processos e métodos envolvidos, e em desenvolvimento, antecipando necessidades e capacitações, bem como potencialidades e não conformidades, restrições de uso e que tais, antecedem a atualização e melhoria dos C\&S, mas realistas e longevas.

\section{Systemigram}

É uma técnica de diagramação sistêmica. Os systemigrams identificam os elementos-chave de um modelo de sistema formal com atenção principalmente as partes, relacionamentos e fluxos. Os systemigrams são redes com nós e links, fluxo, entradas e saídas, início e fim. Os nós são frases nominais que especificam pessoas, organizações, grupos, artefatos e condições. O principal eixo do sistema, o mainstay, deve articular a motivação do modelo para a intenção estratégica, sua missão ou como ela pode ser realizada - sua gestão. Ter esse tipo de informação sobre uma organização é essencial para uma governança eficaz. Os systemigrams fornecem aos atores ou stakeholders do sistema essa compreensão.

Um único systemigram pode ser usado como uma representação de várias redes. Portanto, pode ser uma ferramenta eficazpara estudar a estrutura e operabilidade de qualquer sistema (BOARDMAN e SAUSER, 2013). 
Neste estudo, o SSCIE/EUA (usando osystemigrams) foi concebido a partir da análise de documentos e entrevistas com especialistas em SCIE/EUA, na dimensão de C\&S de SCIE, efetivas no contexto de aplicação, nas quais se acredita ser usado. A técnica fornece um local para a solicitação de informações individuais e coletivas para possibilitar a descoberta de novas idéias relevantes.

A partir do diagrama, a realização da convergência de valores derivados da estrutura da representação gráfica pode fornecer uma base para o estabelecimento de uma cultura comum entre perspectivas. Na figura 1,é apresentado o systemigram do SSCIE/EUA em sua versão.1. Tal cartografia foi elaborada com foco especial nos C\&S da SSCIE/EUA, que endereçam possibilidades, e são efetivos nos contextos de aplicação, nos diversos territórios de atuação, sob o enfoque do conhecimento.

A partir da revisão da literatura, documentos, sítios eletrônicos relacionados a SCIE/EUA e entrevistas realizadas com especialistas brasileiros com relevante experiência em SCIE nos EUA, foi elaborado uma primeira versão.0 do SSCIE/EUA. A versão v.1 do SSCIE/EUA apresentada na figura 1, foi elaborada após novas entrevistas realizadas com renomados especialistas americanos, que sanaram algumas inconsistências. Na figura 2 é destacado 0 principal eixo do sistema, o mainstay. 
Revista Científica do Corpo de Bombeiros Militar de Pernambuco

Artigo Publicado no Vol.05 N.13 - Edição Jul a Dez 2019 - ISSN 2359-4829

Versão on-line disponível em: $\underline{\text { http://www.revistaflammae.com }}$

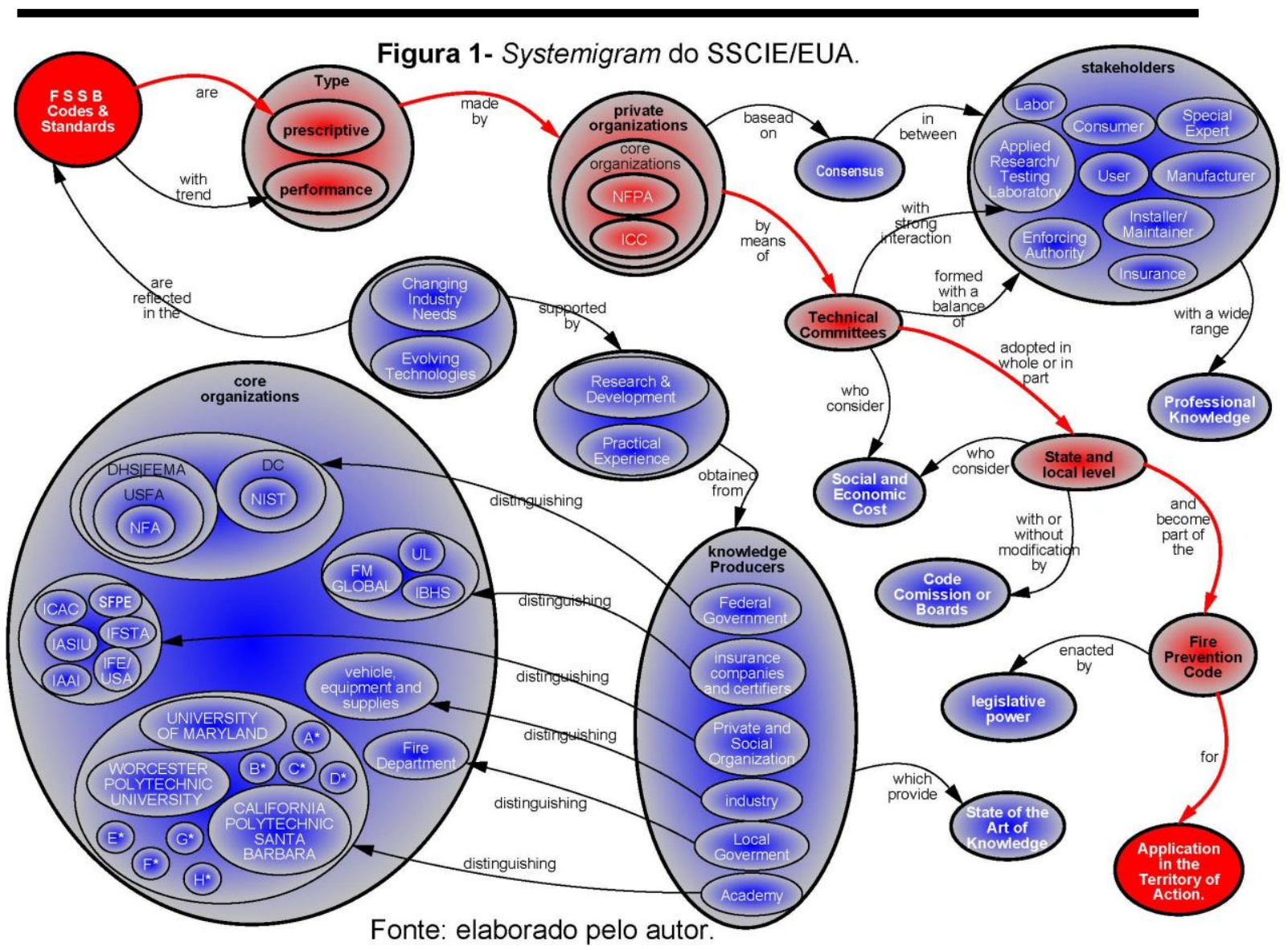

Legenda:

(DHS) U.S. Department of Homeland Security, (FEMA) Federal Emergency Management Agency (USFA), (USFA) United States Fire Administration, (NFA) National Fire Academy, (DC) U.S. Department of Commerce, (NIST) National Institute of Standards Technology. (NFPA) National Fire Protection Association, (ICC) International Code Council, (SFPE) Society of Fire Protection Engineers, (IFSTA) International Fire Service Training Association, (IASIU) International Association of Special Investigation Units and (IFE USA Branch) Institution of Fire Engineers, (IAAI) International Association of Arson Investigators and (ICAC) Insurance Committee for Arson Control. (UL) Underwriters Laboratories, (FM GLOBAL) Factory Global, and (IBHS) Insurance Institute for Business and Home Safety. $\left(A^{*}\right)$ Oklahoma State University, $\left(B^{*}\right)$ Eastern Kentucky, $\left(C^{*}\right)$ University of California/Berkeley, $\left(D^{*}\right)$ University of California/San Diego, $\left(E^{\star}\right)$ California State/San Diego, $\left(F^{\star}\right)$ Princeton, $\left(G^{*}\right)$ University of North Carolina/Charlotte, $\left(\mathrm{H}^{\star}\right)$ University of Texas/Austin. 


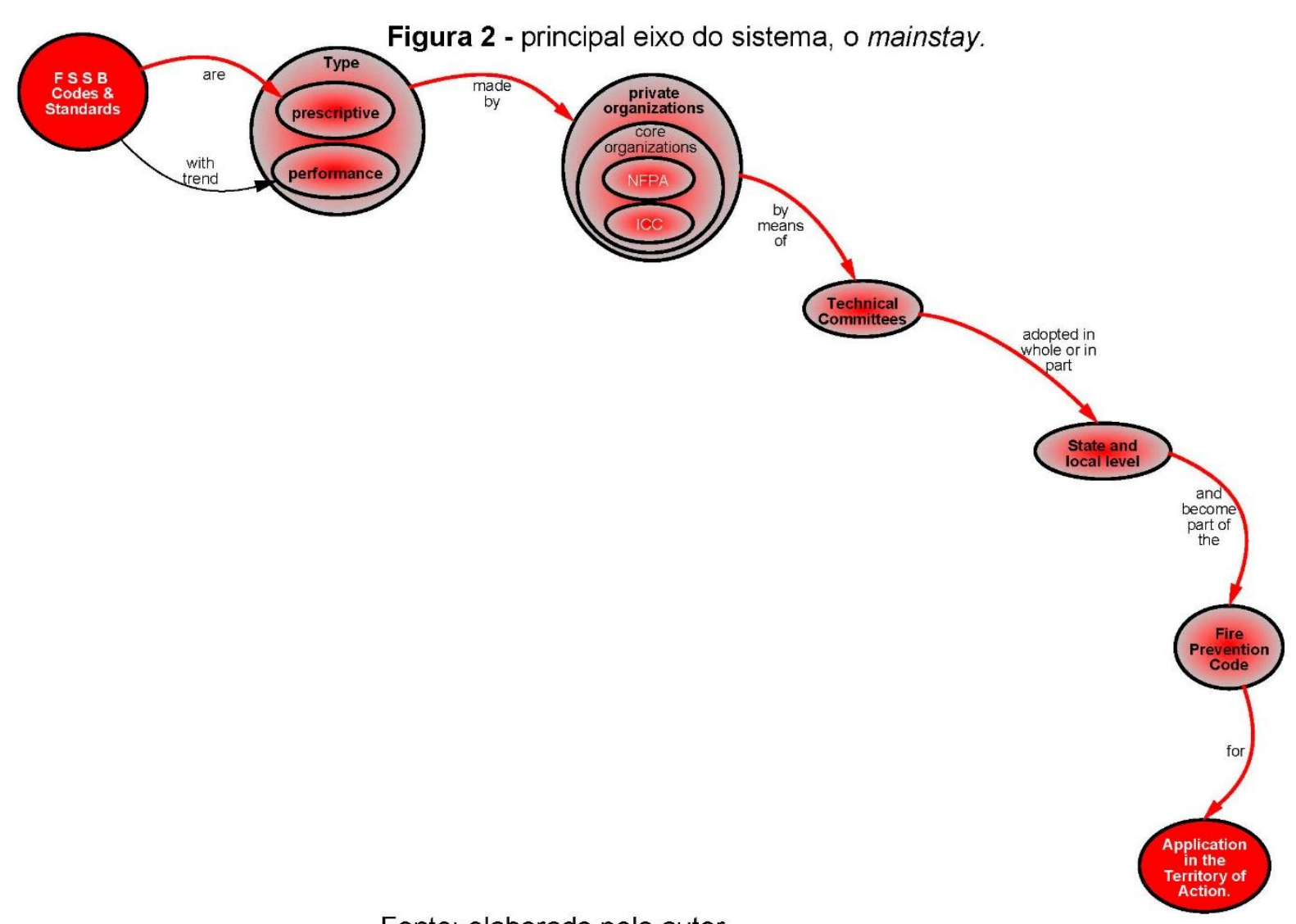

Fonte: elaborado pelo autor.

\section{SISTEMA DE SCIE/EUA}

O SSCIE/EUA tem por função garantir que as legislações, códigos e normas de salvaguarda da vida e do patrimônio incorporem ou se aproximem do Estado da Arte do Conhecimento, observando o custo social e econômico e a legitimação de todos as partes interessadas, em especial a do interesse público, para que sua aplicação seja efetiva ao contexto ou Território de Atuação, refletindo o equilíbrio almejado entre todas as partes interessadas.

Quanto a regulamentação o SSCIE/EUA é descentralizado e não existe um Código Nacional. Os governos locais são autônomos para adotar os C\&Soferecidos por organizações privadas com ênfase na National Fire Protection Association(NFPA) e no International Code Council (ICC). Essas organizações lideram o processo de desenvolvimento de C\&S, buscando 
refletir principalmente o Estado da Arte do Conhecimento, o interesse dos stakeholders e o custo econômico e social. O indivíduo e o coletivo são convidados a participar do desenvolvimento desses documentos. Esse processo de desenvolvimento apoiado por pesquisa e experiência prática, asseguram as necessidades variáveis do setor e as tecnologias em evolução.

Os C\&S são revisados periodicamente por Comitês Técnicos (CT), formados por voluntários - equilibrados entre Usuários, Fabricantes, Consumidores, Trabalhadores, Companhias de Seguros, Especialistas, Instaladores, Laboratórios de Pesquisa Aplicada/Testes e Autoridades de Segurança Pública - com uma ampla gama de conhecimento profissional. O processo de desenvolvimento de C\&S constitui uma verdadeira arena do conhecimento, em que todos podem fazer uma contribuição justa, principalmente nas audiências públicas, onde os C\&S são amplamente discutidos.

Dada a complexidade da regulamentação do SSCIE/EUA e o desejo de ter um sistema tão comum quanto praticável nos EUA, o sistema permanece basicamente prescritivo, com projeto baseado em desempenho sendo executado por exceção sob a cláusula "métodos e materiais alternativos" no código de construção (MEACHAM, 2014).

Para a redação de C\&S são necessários diversos conhecimentos trazidos por atores que compõem o sistema. Dentre os conhecimentos fundamentais para a redação de $C \& S$ que atendam ao Estado da Arte do Conhecimento ou se aproxime dela, destacam-se os conhecimentos científicos (pesquisa básica \& aplicada) principalmente relacionados a dinâmica do fogo. Nos EUA centros de pesquisa públicos e privados financiados pelo Governo Federal realizam pesquisa básica sobre dinâmica do fogo e laboratórios testam e analisam em diversas escalas o comportamento do fogo. As principais competências fundamentais relacionadas ao capital humano de pesquisa são aquelas oriundas da 
Engenharia Química, Engenharia de Proteção Contra Incêndios e Engenharia Mecânica que formam a espinha dorsal da Pesquisa Básica em dinâmica do fogo. O conhecimento produzido por esses atores está sempre disponível para os Comitês, que são responsáveis pela redação final dos $C \& S$, podendo o conhecimento ser atualizado se necessário. Os Comitês integram organizações privadas altamente reconhecidas pela sociedade no domínio da SCl.

Sistema gira em torno dos chamados C\&S que abrangem os mais variados tópicos relacionados à $\mathrm{SCl}$ e empodera os Governos Locais que decidem, auxiliados pelos Comitês, quais C\&S integrarão o Código Local de Incêndio. Apesar do poder discricionário dos Governos Locais, este é acompanhado de perto por um Sistema de Justiça atuante e preparado tecnicamente. O papel do Governo Federal é o de formular a Política Nacional de SCl organizada através de uma ampla rede de financiamento e a United States Fire Administration (USFA) e National Fire Academy, responsáveis respectivamente por quantificar e qualificar o Sistema, ou seja, manter uma base de dados atualizada e capacitar estrategicamente a mão de obra gestora. Os atores públicos ou privados demonstram um alto grau de organização que permitem o conhecimento fluir de modo dinâmico. Os diversos espaços criados sejam eles os Comitês ou associações reúnem diversas perspectivas que enriquecem o processo de criação do conhecimento. Os Corpos de Bombeiros atuando localmente, são como poderíamos dizer os "operadores do sistema", respondendo a efetividade do $C \& S$, fechando o ciclo e retomando o processo de criação do conhecimento.

As vulnerabilidades e ameaças à $\mathrm{SCI}$ são conduzidas pela USFA. Eles prevêem os resultados e riscos e como mitigá-los. Eles solicitam que o NIST, o ATF ou outros laboratórios de pesquisa em uma concessão conduzam um estudo. Pode incluir segurança de bombeiros, saúde, bem-estar, segurança no trânsito, equipamentos de proteção individual, segurança contra acidentes em serviços de incêndio, desastres naturais, emergências não relacionadas a incêndios e proteção de infraestrutura crítica. 
Revista Científica do Corpo de Bombeiros Militar de Pernambuco

Artigo Publicado no Vol.05 N.13 - Edição Jul a Dez 2019 - ISSN 2359-4829

Versão on-line disponível em: http://www.revistaflammae.com

\section{Produtores de Conhecimento de SCIE}

O Estado da Arte do Conhecimento é obtido com os produtores de conhecimento: Governo Federal, Companhias de Seguro e Certificadores, Governo Local, Academia, Indústria e Organizações Sociais. Bryner (2016) relaciona as principais áreas de pesquisa científica que são essenciais para o desenvolvimento de pesquisa e subsidiam a elaboração de C\&S de SCIE e envolvem uma ampla gama de pesquisas, especialmente fundamentos de fogo (por exemplo, química de fogo, física de fogo, dinâmica de fogo), resposta estrutural ao fogo, propriedades de fogo de materiais, comportamento humano e do fogo, tecnologia de sistemas de proteção contra incêndio (por exemplo, detecção, alarme, supressão, controle de fumaça, etc...), tecnologia de bombeiro (equipamento de proteção, equipamento de comando e controle, etc...), meios de supressão de incêndio (por exemplo, névoa, agentes limpos, etc...). À medida que os perigos e riscos evoluem, o mesmo acontece com as necessidades de pesquisa.

Novas tecnologias, como sistemas de armazenamento de energia, exigem novas abordagens para proteção contra incêndios (MEACHAM, 2018).

O Custo Social e Econômico é considerado pelo Governo Local quando da adoção dos C\&S. Os Comitês das principais organizações mencionadas NFPA e ICC, que elaboram os C\&S, frequentemente consideram o custo versus o benefício de incorporar uma nova ciência - existem muitos grupos industriais que fornecem informações, bem como desenvolvem seus próprios padrões por exemplo: American Society of Heating, Refrigerating and AirConditioning Engineers - ASHRAE (no controle de fumaça), American Institute of Steel Construction - AISC (na proteção contra incêndio da construção de aço), American Society for Testing and Materials - ASTM (nos métodos de teste de incêndio), entre outros. Existem muitas centenas de comitês de elaboração de $C \& S$ relacionadas a SCIE.

Os C\&S fornecem uma seleção baseada na ciência de diretrizes de 
SCIE onde os Governos Locais possuem o poder discricionário de adotá-los integralmente ou em partes, transformado em lei, ou não os adotar. Esse sistema de C\&S fornece aos governos locais a flexibilidade para adotar as seções dos códigos que entendem haver uma boa relação de benefícios versus custo, que são então transformadas em lei integrando o Código de Incêndio Local e assim para sua efetiva aplicação (BRYNER, 2016). Assim se espera que o código de incêndio seja efetivo ao ser aplicado no Território de Atuação, ou seja, no contexto em que foi pensado para ser utilizado.

\section{Comitês Técnicos (CT)de C\&S}

As nomeações para um CT são baseadas em perícia técnica, posição profissional, treinamento - diretor, engenheiros de proteção de incêndios, engenheiros elétricos, projetistas de construção e produtos. Eles devem estar comprometidos com a segurança pública dos Incêndios. Os membros do CTdoam seu tempo de voluntariado para o trabalho de diferentes comitês e mudanças nos C\&S. Eles também aceitam solicitações públicas e de campo para as alterações dos $C \& S$. Muitas das mudanças ocorrem a partir da entrada de campo.

Os membros técnicos que oferecem seu tempo, participam aproximadamente de dez dias de reunião em comitês, durante um período de dois a três anos, a fim de fornecer informações e conhecimentos para um determinado padrão (CLEMENS, 2018). Eles realizam teleconferências e coletam dados de pesquisa quando não estão em reunião. Eles também se sentem à vontade para receber contribuições de respondentes, do público e de outros setores de pesquisa para chegar a um consenso para um padrão novo ou atualizado. Eles têm essa revisão constante dos padrões que são atualizados 3 a 5 anos. As publicações são atualizadas neste calendário.

O processo de desenvolvimento de C\&S funciona razoavelmente bem. No entanto, para fazer mudanças significativas é necessário que a pesquisa apoie a mudança e a pesquisa apesar de ser grande não atende à demanda, 
de modo que o ritmo da mudança é lento. Além disso, o governo precisa decidir "quão seguro é o suficiente", e isso pode acontecer fora da arena de criação dos C\&S. Uma melhor articulação pelo governo dos níveis de segurança (risco) alvo ajudaria a resultar em C\&S que atendam a esses níveis (MEACHAM, 2018).

\section{Pesquisa em SCIE}

A pesquisa ou investigação de incêndios nos Estados Unidos é realizada principalmente por três tipos de organizações: Governo Federal, Academia e Companhias de Seguro, sendo que a maior parte da investigação de incêndio urbano realizada é financiada pelo Governo Federal. Os recursos são utilizados pelo USFA e o NIST, organizados sob a Lei de Prevenção e Controle de Incêndio de 1974 e o Department of Homeland Security e a outra parte oriunda dos fundos são enviados à Academia para realizar pesquisas a fim de melhorar a SCI (BRYNER, 2016). As principais universidades que realizam pesquisas de incêndios são aquelas que possuem a graduação de Engenharia de Proteção Contra Incêndios.

Existe uma variedade de escolas que oferecem diplomas relacionados à atividade de bombeiros, mas que fazem pouca pesquisa de incêndios. Ainda existem outras escolas que possuem bons departamentos de ciência da combustão que realizam muitas vezes pesquisa fundamental, ou seja, fornecem a ciência que pode ser usada para melhorar a compreensão sobre 0 fenômeno incêndio e melhorar os $C \& S$.

As companhias de seguro também realizam pesquisas através de laboratórios próprios contribuindo para a melhoria dos C\&S que tipicamente tem como foco seus clientes que fazem trabalho experimental em larga escala com o objetivo de melhorar a SCl. Normalmente esses laboratórios operam testes de produtos e equipamentos que avaliam a SCI. 


\section{Publicações de SCIE}

Dentre os editores especializados em publicações sobre conteúdo de incêndio, existem organizações, como a NFPA, que são amplamente focadas em incêndios. As publicações são tipicamente padrões e guias.

Estes são criados pelos comitês técnicos. Por exemplo, a Sociedade de Engenheiros de Proteção contra Incêndios (SFPE) publica normas, guias e o Manual de Engenharia de Proteção Contra Incêndios (a editora atual é a Springer). Estes são desenvolvidos em grande parte por membros ou outros especialistas, através de comitês do SFPE. O Manual é criado por especialistas de todo o mundo, seja membro do SFPE ou não.

Organizações de padrões associados (por exemplo, ASTM, ASHRAE, etc...) têm conteúdo relacionado a incêndios. Estes são criados pelos comitês técnicos. Alguns, como o ASHRAE Smoke Management Andoo, são desenvolvidos por um grupo de especialistas. Há revistas, como o Fire Safety Journal, publicado pela Elsevier, Fire Technology, publicado pela Springer, Fire and Materials, publicado pela Interscience e outros. Estes são trabalhos de pesquisa revisados por pares. Vários grandes editores também publicam livros, incluindo Elsevier, Wiley, Springer e CRC Press. Normalmente, um autor tem uma idéia, envia para o editor e se houver concordância pode virar um livro.

Quanto a integração ou colaboração entre as várias instituições de pesquisa em SCIE, há pouca colaboração em grande escala (por exemplo, 10 a 20 entidades), uma vez que não há financiamento suficiente para projetos de grande escala. No entanto, existem inúmeras pequenas colaborações (2 a 6 entidades), e colaborações são frequentemente necessárias para obter financiamento de pesquisa.

Infelizmente, a pesquisa é frequentemente conduzida pelas prioridades das agências de financiamento e não necessariamente pelas necessidades da sociedade. Por exemplo, o DHS/USFA investe 25 milhões de dólares por ano em subsídios de Prevenção e Segurança Contra Incêndios, mas apenas 5 a 8 
milhões de dólares em pesquisa de fogo. A National Science Foundation (NSF) dos EUA financia apenas uma pequena quantidade de pesquisas fundamentais sobre o fogo, principalmente a combustão. Não há realmente nenhuma base nacional, embora indiscutivelmente o NIST seja o mais próximo. Não existe uma ferramenta de colaboração tecnológica específica ou dominante (MEACHAM, 2018).

A NFPA produz publicações em pesquisa impressa e on-line sobre SCIE e informações para todos os profissionais em todo o mundo. Na IFSTA as publicações estão on-line e disponíveis em todo o mundo. A OSHA fornece publicações sobre SCIE e saúde relacionadas ao local de trabalho - a Fire Protection Publications (FPP) produz vídeos, manuais de treinamento, e-books, currículos e aplicativos e são uma das maiores faculdades de engenharia para arquitetura e tecnologia nos EUA. Eles também validam muitas das publicações do Corpo de Bombeiros e realizam pesquisas sobre incêndios para a USFA e outros.

\section{CONCLUSÃO}

Nos EUA, o SSCIE é bem organizado e financiado, formado por uma ampla rede de cooperação técnica e científica, com as academias atuando na formação e pesquisa em Engenharia de Proteção Contra Incêndios, que busca identificar os riscos e as garantias construtivas que ajudam a prevenir, controlar e mitigar os efeitos dos incêndios, coexistindo uma vigorosa indústria voltada para esse segmento, o que evidencia um cenário de relevantes contribuições nos aspectos sociais e econômicos, e gera riquezas e impulsiona a produção de conhecimento com a finalidade última na preservação de vidas e secundariamente o patrimônio. Os stakeholders são bem articulados e com as responsabilidades bem definidas, resultando na constante melhoria da SCIE.

De acordo com Dehaan (2007) muito do progresso na redução da frequência de incêndios e das mortes deles advindas é devido ao avanço realizado na melhoria dos $C \& S$. 
Portanto é necessário construir consensos e harmonias nos temas relevantes para os stakeholders, a exemplo dos C\&S de SCIE, que impõe como construir, como equipar e como proceder na preservação e proteção da vida, em primeiro lugar, em toda e qualquer edificação e articular comunidades de práticas em torno das tecnologias nucleadoras do seu mister - propor $C \& S$, vistoriar equipamentos e instalações, fiscalizar quanto ao uso e conformidade, aprovar a instalação e liberar por exemplo os Sistemas de Alarme e Detecção de Incêndios - SDAl, requer compor grupos de aprendizagem com os projetistas, conectando-os permanentemente para o mutuo conhecimento, entendimento e domínio dos ciclos evolutivos das tecnologias aplicadas e das etapas/gestão de projetos, especialmente dos sistemas em uso no território de atuação.

O compartilhamento do olhar e da percepção dos stakeholders, a compreensão dos processos e métodos envolvidos, e em desenvolvimento, antecipando necessidades e capacitações, bem como potencialidades e não conformidades, restrições de uso, antecedem a atualização e melhoria de $C \& S$, que se quer contínuas, mas realistas e longevas.

Com a GC, pode se compreender melhor como funciona o aumento da resiliência e a aplicabilidade mais racional da regulação, integrando vistoriadores, projetistas, engenheiros, arquitetos, dentre muitos outros especialistas, materiais e equipamentos sustentados nas plataformas contemporâneas de comunicação e interação, preconizadas e aplicadas na GC (STEIN, SELL, \& GODINHO, 2018).

Assim o estudo se reveste de notória relevância econômica e social e inaugura um nível de abordagem até então inexistente, descrevendo o SSCIE/EUA como olhar sistêmico, buscando identificar as principais interações e abordando dimensões qualitativas, à luz do conhecimento, e podendo ser ponto de partida para o desenvolvimento de ações envolvendo a governança e capacitação do SSCIE/BR. 


\section{Pesquisa Futura}

São grandes os desafios e demandas colocadas em face de recursos econômicos e financeiros públicos escassos e decrescentes, insuficiência de conhecimento aplicado, dos mais básicos (estatísticas nacionais confiáveis sobre incêndios, integradas e compartilhadas, por exemplo), no urgente enfrentamento das lacunas e demandas por tecnologias e ativos operacionais e de gestão, na governança interna e relacional, conhecimentos ainda por gerar, apreender ou adaptar e adotar, necessários às corporações.

Diante do bem engendrado SSCIE/EUA, quando voltamos o olhar para realidade brasileira observamos que existe um descompasso entre as demandas e a capacidade de resposta dos CBM's. O não reconhecimento da Ciência do Fogo no Brasil, por exemplo, agrava a emergência.

O mestrado em curso no PPGEGC $7 /$ UFSC, identificando os conhecimentos fundamentais no SSCIE/EUA, reconhecida e tomada como referência mundial, se reveste de importância para a compreensão do SSCIE/BR, visando seu fortalecimento com a melhoria continua na sua rota estratégica de evolução e sua resiliência, que lastreadas no conhecimento, que dinamicamente acompanha pesquisas e inovações incrementais de aplicação, e a partir desses conhecimentos, políticas públicas e/ou privadas voltadas à SCIE poderão atender efetivamente à realidade local e nacional. "Pensar globalmente e agir localmente".

\section{BIBLIOGRAFIA}

BOARDMAN, J., \& Sauser, B. Systemic Thinking. Hoboken: Wiley, 2013. BRYNER, N. (Stein,S. Entrevistador), 2016.

\footnotetext{
${ }^{7}$ PPGEGC - Programa de Pós-graduação em Engenharia e Gestão do Conhecimento da Universidade Federal de Santa Catarina.
} 
CHECKLAND, P. Systems Thinking, Systems Practice. Chichester: Wiley, 1999.

CLEMENS, M. (S. Stein, Entrevistador), 2018.

DALKIR, K. Knowledge Management in Theory and Practice ( $3^{\mathrm{a}}$ ed.). London: MIT Press, 2017.

FEDERAL EMERGENCY MANAGEMENT AGENCY. America Burning Revisited. Virginia, 1987.

GODINHO, M. J. (S. Stein, Entrevistador), 2018.

MEACHAM, B. Fire From First Principles. Em P. Stollard. New York: Routledge, 2014.

MEACHAM, B. J. (S. Stein, Entrevistador), 2014.

STEIN, S., SELL, D., e GODINHO, M. J. Melhoria Contínua na Segurança Contra Incêndio em Edificações. Em F. S. Unicamp (Ed.), Segurança Contra Incêndio em Edificações: Recomendações (p. 200). Vitória, ES, 2018. 